\title{
Habituation of dairy heifers to milking routine-Effects on human avoidance distance, behavior, and cardiac activity during milking
}

\author{
T. Kutzer, M. Steilen, L. Gygax, ${ }^{1}$ and B. Wechsler \\ Federal Food Safety and Veterinary Office FSVO, Centre for Proper Housing of Ruminants and Pigs, Agroscope, \\ Institute for Livestock Sciences ILS, Tänikon, 8356 Ettenhausen, Switzerland
}

\begin{abstract}
The onset of lactation marks a significant turning point in a heifer's life, and prior experience with the milking routine could have positive effects on animal welfare and productivity. The objectives of this multifarm $(\mathrm{n}=5)$ study were to investigate $(1)$ whether prelactation training sessions affected behavior during milking, cardiac activity, human avoidance distance, and milk yield, and (2) whether these responses would be modified by the heifer's initial level of fear of humans. Trained heifers $(\mathrm{TH}, \mathrm{n}=30)$ experienced the routine in the milking parlor on at least $10 \mathrm{~d}$ prepartum, whereas untrained heifers $(\mathrm{UH}, \mathrm{n}=29$ ) entered the parlor for the first time after calving. Behavior and cardiac activity were recorded on d 1 and 7 after calving, and an avoidance test was carried out on the day of integration into the dairy herd as well as on d 1, 7, and 28 postpartum. Each animal's initial level of fear of humans was classified as high or low based on the first human avoidance distance measured toward an unknown person. Results showed that TH showed less stepping and kicking during the udder preparation phase in the parlor and $\mathrm{UH}$ had higher probabilities to put their ears flat on the head, clamp their tail between the hind legs, and have their eyes wide open throughout the different phases in the milking parlor. Heart rate decreased from $\mathrm{d} 1$ to 7 , increased from before to during and to after milking and was slightly elevated in TH compared with UH. Milk yield did not differ between TH and UH. Human avoidance distance was not influenced by training, but distance decreased in heifers with a high initial level of fear of humans across repetitions of the test, whereas heifers with a low initial level of fear of humans had generally short avoidance distances. However, initial level of fear of humans neither determined behavior and
\end{abstract}

Received August 22, 2014.

Accepted April 15, 2015.

${ }^{1}$ Corresponding author: lorenz.gygax@agroscope.admin.ch heart rate during milking nor milk yield of TH and UH. The results indicate that the training regimen applied in the present study habituated heifers, to some extent, to the milking routine.

Key words: dairy heifer, milking routine, fear of humans, adaptation, expressive behavior

\section{INTRODUCTION}

During the periparturient period, transition heifers experience various changes in their housing conditions. They are introduced to the housing system of the dairy herd, where they may, for example, have to start using cubicles as a lying area. They are confronted with a new social environment, the dairy herd, resulting in aggressive behavior toward the introduced animals (Neisen et al., 2009). Moreover, human-animal interactions become more frequent during introduction to the dairy herd, at calving, and during milking (Hemsworth et al., 1989). Finally, heifers have to get used to the milking routine, including agonistic interactions in the waiting area in front of the milking parlor and management procedures during milking (Wicks et al., 2004; Sutherland and Huddart, 2012). As a consequence, transition heifers are likely to show behavioral and physiological responses to these multiple stressors (Van Reenen et al., 2002; Eicher et al., 2007).

With the aim to reduce the number of stressors acting on transition heifers, several studies investigated the effects of familiarizing heifers with the milking parlor before calving on indicators of stress, animal welfare, and productivity. As a behavioral measure of stress during milking, stepping and kicking have been used to measure the consequences of such training (Eicher et al., 2007; Sutherland and Huddart, 2012), to assess the effect of the human-animal relationship on behavior in the parlor (Hemsworth et al., 2000; Rousing et al., 2004; Sutherland and Dowling, 2014), and to quantify individual differences in responsiveness of primiparous dairy cows to milking (Van Reenen et al., 2002).

Furthermore, heart rate and heart rate variability have been used as indicators of stress during milking of 
dairy cows (Gygax et al., 2008; Sutherland et al., 2012; Kovács et al., 2014). For example, Rushen et al. (1999) reported that the presence of an aversive handler increased heart rate during milking, and Van Reenen et al. (2002) found that high heart rate responses during milking in primiparous dairy cows were associated with enhanced inhibition of milk ejection. With regard to heart rate variability, different measures have been calculated to assess changes in sympathetic and vagal activation of the autonomic nervous system (von Borell et al., 2007). The square root of the mean squared difference of successive interbeat intervals (RMSSD) indicates vagal activation, whereas the standard deviation of all interbeat intervals (SDNN) indicates sympathetic or vagal activation. In addition, the ratio between RMSSD and SDNN is used to monitor changes in the sympatho-vagal balance.

As primiparous cows start entering the milking parlor, interactions with humans become more frequent, and the human-animal relationship is likely to change. To measure this relationship, Waiblinger et al. (2003) developed an avoidance distance test characterized by high between-experimenter repeatability (Windschnurer et al., 2008). Using similar tests, Rousing et al. (2004) and Dodzi and Muchenje (2011) reported that stepping in dairy cows during milking was associated positively with their avoidance distance toward humans. Moreover, the quality of the human-animal relationship measured in terms of avoidance distance or other fear-indicating behavior was found to have positive effects on milk yield (Breuer et al., 2000) and udder health (Ivemeyer et al., 2011) in dairy cows.

To adapt primiparous cows to milking, Das and Das (2004) massaged the heifers' udders during late pregnancy and found that this handling resulted in reduced restlessness during milking and a lower frequency of urination and defecation, indicating a reduction of fear compared with the responses of nonmassaged heifers in the control group. Moreover, milk flow rate was increased in massaged animals. Similarly, Bertenshaw et al. (2008) brushed heifers in the weeks preceding calving and found that handled animals tended to show less kicking during milking and had a faster milk letdown compared with control heifers receiving minimal handling during routine husbandry. Hemsworth et al. (1989) reported that human presence at the time of calving in primiparous cows reduced the number of "flinch, step, and kick" responses but did not significantly influence heart rate during milking.

In a few studies, heifers were taken through the parlor without milking in the prepartum period to habituate them to this management procedure. It was found that duration of milking was longer and milk yield higher in experienced heifers (Wicks et al., 2004), and that they had a lower heart rate on $\mathrm{d} 1$ of lactation (Schwalm et al., 2012) compared with inexperienced heifers. Contrary to these positive effects, Eicher et al. (2007) reported that experienced heifers tended to kick more during milking, and the results of Sutherland and Huddart (2012) indicated that heifer temperament was important in addition to training. They found that trained heifers defined as low responders based on exit time from a restraint device flinched, stepped, and kicked more during attachment of milking clusters than untrained low responders, and that milk yield was lower in trained than untrained high responders. Whereas these studies were typically carried out on a single farm, a multifarm approach was chosen in the present study. Moreover, we tested expressive behaviors shown during milking for their suitability to assess the effect of training on heifer behavior.

The aim of the present study was to investigate the effect of habituating heifers to the milking parlor on behavioral and physiological stress responses as well as productivity on 5 commercial dairy farms. Trained heifers experienced the routine in the milking parlor on at least $10 \mathrm{~d}$ prepartum, whereas untrained heifers entered the parlor for the first time after calving. In addition to previously used indicators to assess the effect of habituation (stepping and kicking, heart rate and heart rate variability, milk yield), we measured the animals' expressive behavior (body posture, tail carriage, ear posture, head posture, eye aperture) during the milking routine. Finally, we carried out an avoidance distance test on the day of integration into the dairy herd as well as on d 1, 7, and 28 postpartum and classified heifers' initial level of fear of humans as high or low based on the first human avoidance distance measured toward an unknown person. We expected that avoidance distance would decrease over the study period, especially in heifers with a high initial level of fear of humans, and more so in the trained than in the untrained heifers. In respect to the behavior during milking, we expected that trained heifers would show fewer behavioral signs of stress; that is, less stepping and kicking and would be less likely to show a curved back, lowered head, tail clamped between the legs, and eyes wide open. In respect to the ear position (i.e., the probability of having the ears flat on the head) we did not have a directed hypothesis due to the limited previous studies in cattle (Proctor and Carder, 2014). We also expected fewer physiological signs of stress in the trained heifers; that is, a lower heart rate, higher RMSSD, lower SDNN, and higher RMSSD-to-SDNN. Finally, trained heifers 
were expected to have higher milk yield than untrained heifers.

\section{MATERIALS AND METHODS}

\section{Farms and Animals}

The study was carried out from June to December 2012 on 5 commercial dairy farms in Switzerland $(\mathrm{n}=$ 4) and Liechtenstein $(n=1)$, with herd sizes varying between 33 and 78 lactating cows. On all farms, cows were housed in cubicle housing systems, including an outside run, and had access to pasture during summer. Floors were partly slatted, and solid floors were cleaned by manure scrapers. Milking parlors were designed as herringbone $(\mathrm{n}=3$; with $2 \times 6,2 \times 5$, and $2 \times 4$ places, respectively) or autotandem $(\mathrm{n}=2$; with $2 \times 3$ and $1 \times 3$ places, respectively). All herds were milked twice a day (between 0400 and $0530 \mathrm{~h}$ and between 1600 and $1700 \mathrm{~h}$ ). Average milk production level per farm ranged from 7,705 to $8,866 \mathrm{~kg} / \mathrm{cow}$ and lactation.

Seventy-two heifers (64 Brown Swiss, 5 Holstein Frisian, 3 Swiss Simmental) were included in the experiment. Mean age of heifers at first calving was 29.3 mo $( \pm 3.4 \mathrm{SD})$. All animals were housed in accordance with the Swiss animal welfare regulations, and the study was approved by the Cantonal Veterinary Office (Frauenfeld, Thurgau, Switzerland, application number F4/10) under the Swiss Animal Welfare Act 2005.

\section{Treatment and Experimental Design}

On the study farms, 72 heifers with estimated calving dates from June to November 2012 were introduced to the herd at $14.5 \mathrm{~d}$ (median; range -1 to $64 \mathrm{~d}$ ) before expected calving. The introduction took place with at least 2 heifers at the same time, and heifers were allocated randomly to 2 treatment groups blocked within farm: trained heifers $(\mathbf{T H})$ received training in the milking parlor starting on the day of introduction to the herd, whereas untrained heifers (UH) were exposed to the milking routine for the first time after calving. Training consisted of a first week in which heifers could choose voluntarily whether or not to go through the milking routine. Thereafter, heifers were driven to the milking parlor together with the cows and went through the milking routine. The routine consisted of passing the milking platform and being exposed to noises of milking and tactile contact at the udder by the milking staff, but did not include attachment of milking cups. During the first week of training, $89 \%$ of $\mathrm{TH}$ entered the milking parlor voluntarily and $69 \%$ never missed a milking time after a first successful passage. After up to 10 forced passages in the second week of training, the remaining $11 \%$ of $\mathrm{TH}$ also attended further milking times voluntarily. We included $\mathrm{TH}$ in the evaluation only when they had gone through the milking routine at least 10 times $(\mathrm{TH}, \mathrm{n}=30)$. In total, these $\mathrm{TH}$ experienced the milking routine 35.5 times in the median (range 14 to 98 times). These heifers were introduced into the herd at least $10 \mathrm{~d}$ before calving. Accordingly, we considered only those UH that were introduced to the herd at least $10 \mathrm{~d}$ before calving $(\mathrm{UH}, \mathrm{n}=29)$.

\section{Behavior in the Milking Parlor}

All heifers were milked for the first time within 24 $\mathrm{h}$ postpartum. On d 1 and 7 postpartum, heifers' behavior in the milking parlor was recorded live by 1 of 2 trained observers (M. Steilen, T. Kutzer) standing in the operator pit; therefore, blinding of the observers was not possible. The observers scored several milkings in parallel to train the recording. After training, they reached a high level of agreement in that they never disagreed in respect to the expressive behavior (see below) and deviated at most by 1 observed step or kick. Eighty percent of the observations were conducted by one of the observers (M. Steilen) and the split between the observers was roughly balanced between farms and treatments. Due to logistics and time limitations (e.g., parallel calvings on several farms), it was not possible to observe the very first milking in all heifers. As a consequence, first milking observed varied from the first to third milking, evenly distributed among farms and between TH and UH.

Behavioral observations included stepping (weight displacement with the foot elevated less than $15 \mathrm{~cm}$ off of the ground) and kicking (in any direction with the hoof lifted at least $15 \mathrm{~cm}$ ), recorded separately for 2 phases: udder preparation (before attachment of the first milking cup) and milking (from attachment of the first until removal of the last milking cup). As we did not use electronic data collection devices, we could not analyze the length of the different phases, but the duration of milking was recorded using a stop watch. Therefore, stepping and kicking rates were calculated for the milking phase, whereas absolute numbers of steps and kicks were evaluated for the udder preparation phase.

Expressive behavior of animals was observed separately at 3 points in time: during entry into the milking parlor before udder cleaning (i.e., when all 4 legs of the heifers were in the milking stall), once during udder preparation and milking, and during exit from the milking parlor (after detachment of all cups; i.e., when 
the milking stall was opened but the heifers were still in the stall with all 4 legs). Expressive behavior included body posture (straight topline vs. curved back), tail carriage (hanging tail vs. tail clamped between hind legs), ear posture (ears put flat vs. ears hanging/ears turned forward), head posture (relaxed head position vs. lowered head), and eye aperture (eyes half open vs. eyes wide open). Elimination behavior in the milking parlor was close to inexistent in the current study and therefore the occurrence of the curved top-line did not just co-occur with elimination behavior.

\section{Cardiac Activity}

Cardiac activity was measured noninvasively by using the transmitters and the recording facilities of the Polar Team² Pro system (Polar Electro Oy, Kempele, Finland) during milking on d 1 and 7 postpartum. Electrodes of the Polar equine belts were placed by using the method described by Hopster and Blokhuis (1994). To increase the electrode-to-skin contact, the animals were shorn in the appropriate spots and a commercial electrode gel was applied. On the day of integration into the herd, the chest belt of the Polar system was put on heifers without further equipment for approximately 1 $\mathrm{h}$ to habituate them to the procedure. In a pilot test, heifers did not show any signs of defensive behavior after the belt was put on and their heart rate decreased to a normal level within 5 to 10 min.

On $\mathrm{d} 1$ and 7 postpartum, cardiac activity of heifers was measured for 3 min each during 3 phases. The first phase started about 20 min before milking to record daily baseline values. The second phase included the time during milking, and the third phase started about 20 min after milking to reflect recovery values. Twenty min before milking, the heifers typically waited in the waiting area of the milking parlor. Three of the farms either had a dedicated waiting area or used the outdoor run as the waiting area, whereas the other 2 farms used a split-off alley along lying cubicles as the waiting area. On all farms fresh feed was available after milking and therefore heifers were usually feeding 20 min after their milking.

Heart rate per minute (defined as number of RR intervals; nRR) and 3 measures of heart rate variability [RMSSD (ms), SDNN (ms), and ratio between RMSSD and SDNN] were computed in $\mathrm{R}$ ( $\mathrm{R}$ Core Team, 2013) after conducting the automatic correction of RR data by using the given standard setup of the Polar Equine Software 4.0 (v. 4.00.024 H, Polar Electro $\mathrm{Oy}$ ) in the low-filter correction modus. All evaluated segments had an error rate of less than $5 \%$. Due to violated assumptions in the statistical evaluation, 5 single values with heart rates over 150 were excluded from the analysis.

\section{Avoidance Distance Test}

Heifers were subjected to an avoidance distance test (ADT) carried out in the barn. They were tested 4 times, namely on the day of the integration of a heifer into the herd (d 0 ) and on d 1, 7, and 28 postpartum. For a given animal and day, the ADT was carried out twice with a time lag of 5 min, once with a known and once with an unknown person. The farmer, a stockperson, or a milker served as known persons for a given animal. The first and second authors (T. Kutzer, M. Steilen) served as unknown persons and were unfamiliar to the experimental animals only before initial testing. All these persons were involved in the habituation process and could therefore not be blinded in respect to the training status of any given heifer. Animals were approached only when they were standing and at a speed of 1 step per second starting from a distance of $4 \mathrm{~m}$ and applying the procedure described by Waiblinger et al. (2003; for the reliability of the method, see Windschnurer et al., 2008). When the animal started to move away or turned its head aside, the person stopped immediately, and the avoidance distance was recorded as the distance between the person's hand and the animal's muzzle. If an animal could be touched at the cheek or the lateral nose but turned its head away within $5 \mathrm{~s}$, the distance was recorded as $0.05 \mathrm{~m}$. If the person's hand could rest on the cheek or the lateral nose for at least $5 \mathrm{~s}$, the distance was recorded as $0 \mathrm{~m}$.

The initial level of fear of humans was categorized for all heifers based on the avoidance distance observed on d 0 when the test was carried out by the unknown person. Animals with an avoidance distance greater than $0.3 \mathrm{~m}$ and equal to or smaller than $0.3 \mathrm{~m}$ were denoted as having a high ( $\mathrm{TH}, \mathrm{n}=15$; $\mathrm{UH}, \mathrm{n}=16$ ) and low ( $\mathrm{TH}, \mathrm{n}=15 ; \mathrm{UH}, \mathrm{n}=13$ ) initial level of fear of humans, respectively. At least 1 animal was included in each treatment group and initial level of fear of humans on each farm.

\section{Milk Yield}

Milk yield was compared between TH and UH. One $\mathrm{TH}$ and $1 \mathrm{UH}$ heifer were culled during the data collection period; therefore, the sample was reduced by 1 animal per group. Total milk yield $(\mathrm{kg})$ and average milk yield per minute during milking were recorded automatically by the yield indicator of the milking device or manually by using a hanging scale on d 1 and 7 after parturition. 
Total milk yield and lifetime daily milk yield during the first $100 \mathrm{~d}$ in lactation were calculated based on the official milk control measurements as reflected in the herd management information system BrunaNet (Schweizer Braunvieh Zuchtverband, Zug, Switzerland).

\section{Statistical Analysis}

Statistical analysis was performed in R 3.0.1 (R Core Team, 2013) by using the package lme4 (Bates et al., 2014). A maximum model was subjected to an allsubset analysis for each outcome variable by using the function dredge of the MuMIn package (Barton, 2014). The maximum model included all predictors as listed below and all their potential interactions. The minimal model, including only a constant, corresponded to the null hypothesis that no explanatory variable had an influence and that the response varied randomly around a general mean. The choice among the different models was based on the Bayesian information criterion, which provides a model weight [i.e., a probability for each model in the set of the given data; see Reefmann et al. (2012) for the general approach on informationcriterion based model selection and Gygax et al. (2013) for the use of the Bayesian information criterion in this approach]. In addition, the evidence ratios, calculated as the model weight of the specific model divided by the model weight of some other model, were specified. Model assumptions were checked by a graphical analysis of residuals in respect to normal distribution of the errors and random effects as well as homoscedasticity of the errors. If necessary, data of outcome variables were transformed (Table 1). In the case of the binary variables, we applied generalized models using the binomial distribution and we graphically checked the absence of bias in the mean errors. Dependencies in the experimental design (nesting, repeated measurements) were reflected by the specific random effects used. In most of the models, the random effects consisted of the heifer identity nested in farms. The level test day was further nested at the lowest level for the heart-rate variables and the avoidance distance test (several measurements on each test day), and the level of the individuals was dropped for the evaluation of the production data (each measure taken only once per heifer; Table 1).

The fixed effects of the maximum models slightly varied according to the outcome variable. For behavior during milking and cardiac activity, the fixed effects were treatment group (factor with 2 levels: TH, UH), observation day (factor with 2 levels: $\mathrm{d} 1,7$ ), and initial level of fear of humans (factor with 2 levels: low, high). The models on cardiac activity additionally included the phase (factor with 3 levels: before milking, during milking, after milking).

The ADT and productivity data were compared between 2 treatment groups (factor with 2 levels: TH, UH). In addition, the fixed effects person (factor with 2 levels: known, unknown), observation day (factor with 4 levels: d 0, 1, 7, 28), and initial level of fear of humans (factor with 2 levels: low, high) were used as predictors for the ADT data, and initial level of fear of humans (factor with 2 levels: low, high) and age at first calving (continuous) were used as predictors for the productivity data.

\section{RESULTS AND DISCUSSION}

\section{Model Selection}

For most the outcome variables, the null model was the most probable model $\left(\mathrm{ER}_{0}=1\right.$ in Table 1$)$; that is, no statistical support for an influence of any of the analyzed fixed effects was noted. For some outcome variables, the most probable model was only weakly supported (i.e., less than 4 times more probable than the null model; bold italic numbers in $\mathrm{ER}_{0}$ in Table 1 ). Several of the most probable models that included the difference between UH and TH reached an evidence ratio larger than one-fifth in relation to the overall most probable model, therefore weakly supporting such an effect. All strongly supported effects (bold numbers in $\mathrm{ER}_{0}$ in Table 1) as well as the weakly supported effects of training (bold numbers in $\mathrm{ER}_{\mathrm{mp}}$ in Table 1) will be further discussed.

\section{Behavior in the Milking Parlor}

There was weak evidence that TH stepped and kicked less often (during the udder preparation phase; Figure 1), had a lower probability of ears put flat on the head (during all 3 phases), a lower probability for the tail clamped between the hind legs (during all 3 phases), and a lower probability for having the eyes wide open (during entry and exit) compared with UH (Table 1). Also, the observation that the probability for having eyes wide open decreased from d 1 to 7 during the preparation or milking phase was strongly supported [model estimates including $95 \%$ CI based on a parametric bootstrap; d $1=0.29(0.00 ; 0.43), d 7=0.07(0.00$; $0.15)$; Table 1].

These results indicated that the training regimen applied in the present study habituated heifers to the milking parlor, as they showed less restlessness behavior, such as stepping and kicking, and were less likely 


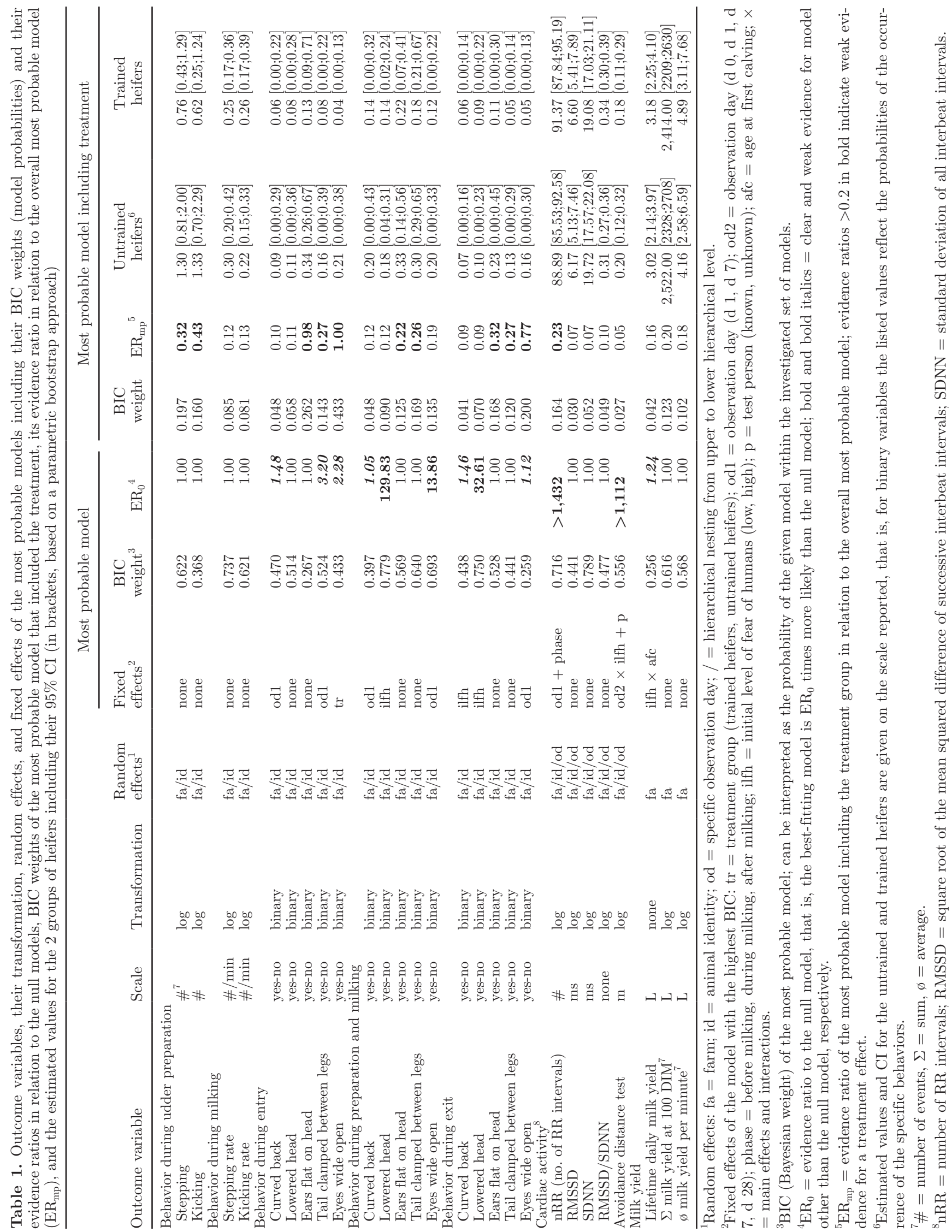




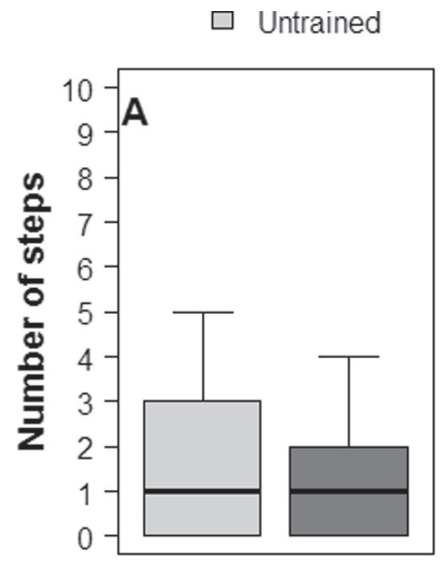

$\square$ Trained heifers
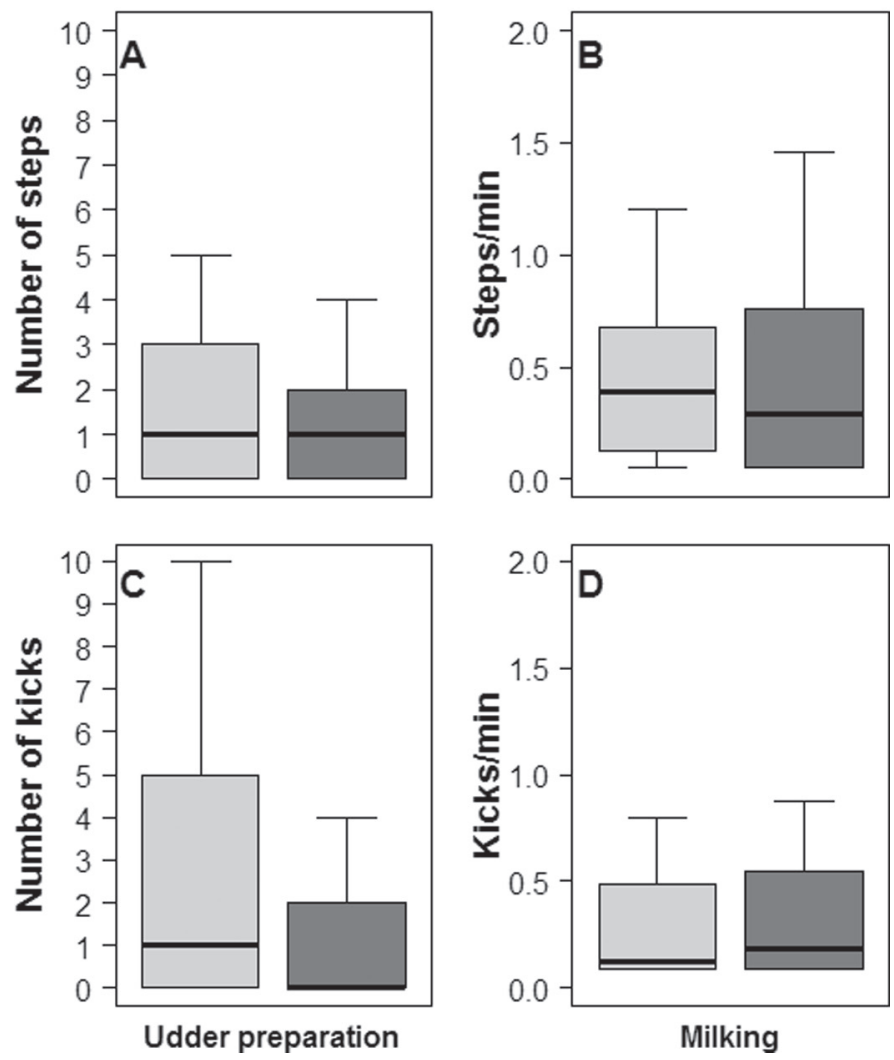

Figure 1. Number of steps (A) and stepping rate (B), as well as number of kicks $(\mathrm{C})$ and kicking rate (D), shown by trained and untrained heifers during udder preparation and milking, respectively. Box and whisker plot of raw data: boxes $=$ first and third quartiles; thick line $=$ median; whiskers $=$ data range

to show expressive behavior typically associated with negative situations. Contrary to these results, trained heifers tended to kick more than untrained heifers in the study by Eicher et al. (2007), and this tendency was noted for trained heifers characterized as low responders based on exit time from a restraint device in an experiment carried out by Sutherland and Huddart (2012). In line with our results, intensification of human-animal interactions during late pregnancy resulted in less kicking and fewer "flinch, step, and kick" responses in trained heifers compared with untrained heifers in the studies by Bertenshaw et al. (2008) and Hemsworth et al. (1989), respectively.

The results on expressive behavior further supported the effect of training in that $\mathrm{TH}$ compared with $\mathrm{UH}$ were found to be less likely to show behavior associated with negative situations in previous studies and in that the probability for having the eyes wide open decreased for $\mathrm{d} 1$ to 7 when habituation was expected. Kauke and Savary (2010) reported that exposure to noise and vibration increased the numbers of animals that kept their tail between the legs, supporting that this behavior reflects a negative situation. With regard to eye aperture, Sandem et al. (2004) showed that opening of an umbrella in front of cows caused an increase in the percentage of eye white, and Sandem and Braastad (2005) found that eye-white percentage was larger when cows were separated from their calf compared with when they were reunited with the calf. In studies with sheep, high frequencies of ear posture changes and specific ear postures were associated with a situation of presumed negative emotional valence (i.e., separation from the group; Reefmann et al., 2009; Boissy et al.; 2011). In the present study, the lower probability of ears put flat on the head was paralleled by a lower probability for the tail clamped between the hind legs and a lower probability for having eyes wide open in trained heifers. We would therefore conclude that this ear posture is likely to be shown in situations of negative valence. However, Proctor and Carder (2014) found that dairy cows showed backward ears that were defined very similarly to our ears put flat on the head for a longer duration during stroking compared with prestroking or poststroking periods.

In addition to the effects mentioned above, strong evidence was observed that the probability of a lowered head was higher in the heifers with high compared with the heifers with low initial levels of fear of humans [during preparation or milking: low $=0.06(0.01 ; 0.13)$, high $=0.35(0.17 ; 0.48)$; during exit: low $=0.03(0.00 ; 0.11)$, high $=0.26(0.00 ; 0.46)$; Table 1$]$. This coincides with observations by Hemsworth et al. (2011) that increased cortisol concentrations in cattle observed at the abattoir were associated with increased levels of head-down postures.

\section{Cardiac Activity}

With strong statistical support, nRR increased across phases from before milking to during milking to after milking (Figure 2A; Table 1) and decreased from d 1 to 7 [during milking: d $1=96.30(92.63 ; 100.22)$, d 7 $=84.31(80.89 ; 87.67)]$. There was weaker statistical support that TH had higher nRR than UH (Figure 2A, Table 1). The outcome variables of heart rate variability did not seem to be affected by the investigated fixed effects (Figure 2B-D). In accordance with the results of Schwalm et al. (2012), we found a reduction in the heart rate of the heifers when they had been milked for $1 \mathrm{wk}$ compared with the heart rate during the first milking. This reduction indicates clearly that the animals habituated to the milking routine. However, the training regimen applied in the present study did not result in a 


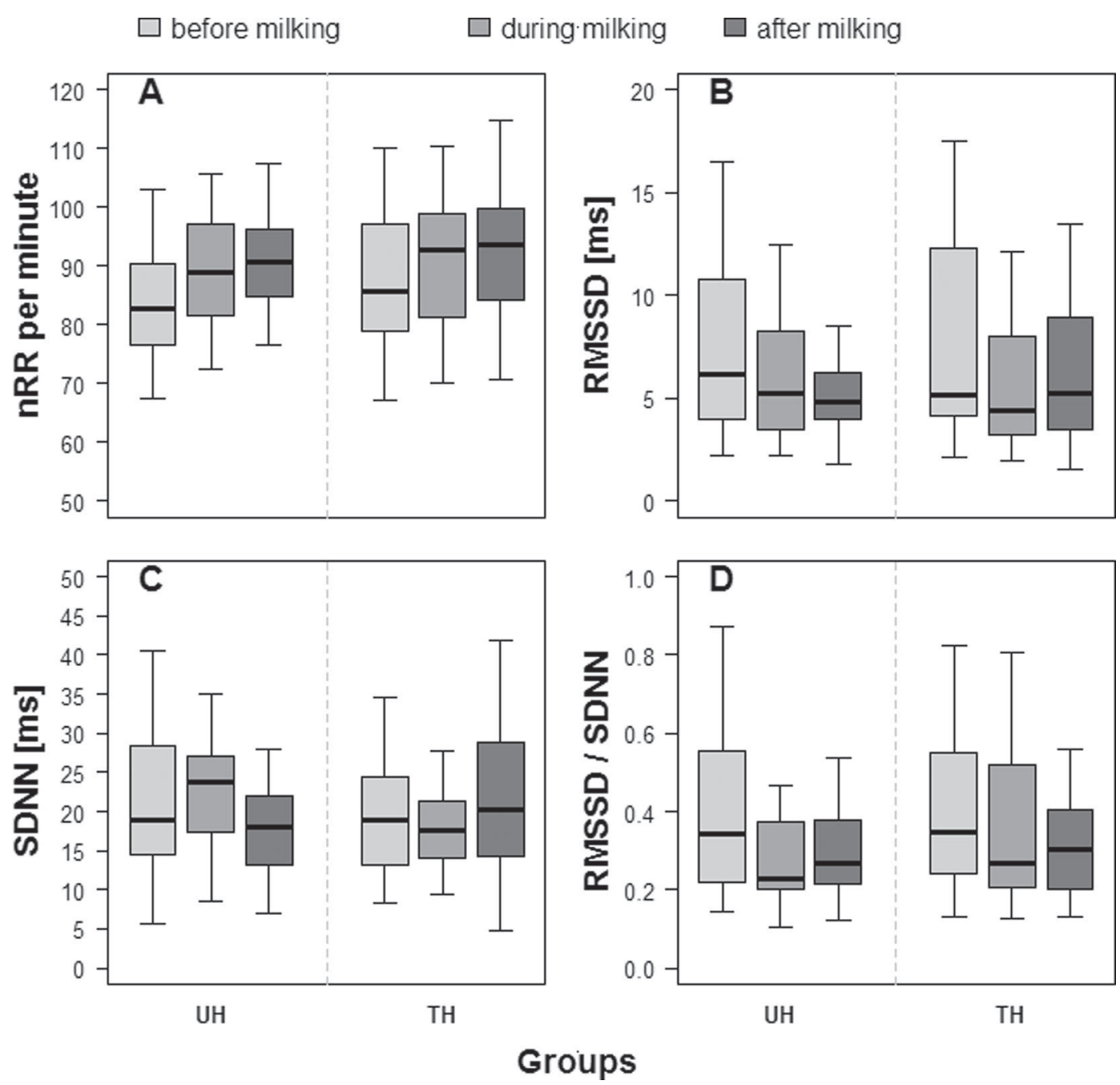

Figure 2. Heart rate (nRR, $\min ^{-1}$; A), square root of the mean squared difference of successive interbeat intervals (RMSSD, ms; B), standard deviation of all interbeat intervals (SDNN, ms; C), and ratio between RMSSD and SDNN (D) of trained (TH) and untrained (UH) heifers during the phases before milking, during milking, and after milking. Box and whisker plot of raw data: boxes = first and third quartiles; thick line $=$ median; whiskers $=$ data range.

lower but in a slightly increased heart rate level in the trained compared with the untrained heifers, though the difference observed of about 2.5 beats/min does not seem to be highly relevant physiologically. The increase in $\mathrm{nRR}$ from before milking to during milking to after milking suggests that heifers were aroused increasingly from waiting for being milked to milking and to feeding. This may have partly been the effect of a split-off alley along lying cubicles being used as the waiting area on 2 farms.

\section{Avoidance Distance Toward Humans}

Human avoidance distance was not influenced by training. Distance decreased in heifers with a high initial level of fear of humans across repetitions of the test, whereas heifers with a low initial level of fear of humans had generally short avoidance distances (Figure 3; Table 1). Avoidance distance of heifers was shorter on average toward a known person than toward an unknown person [e.g., on d 1: distance to known person $=0.17(0.11 ; 0.26)$; distance to unknown person $=0.21(0.14 ; 0.34)]$. Our results support the view that the avoidance test applied is a valuable measure of the human-animal relationship (Windschnurer et al., 2008). As expected, the distance observed in heifers initially with a high level of fear of humans decreased over time, and the heifers more readily accepted approach by a known than an unknown person in this test. 


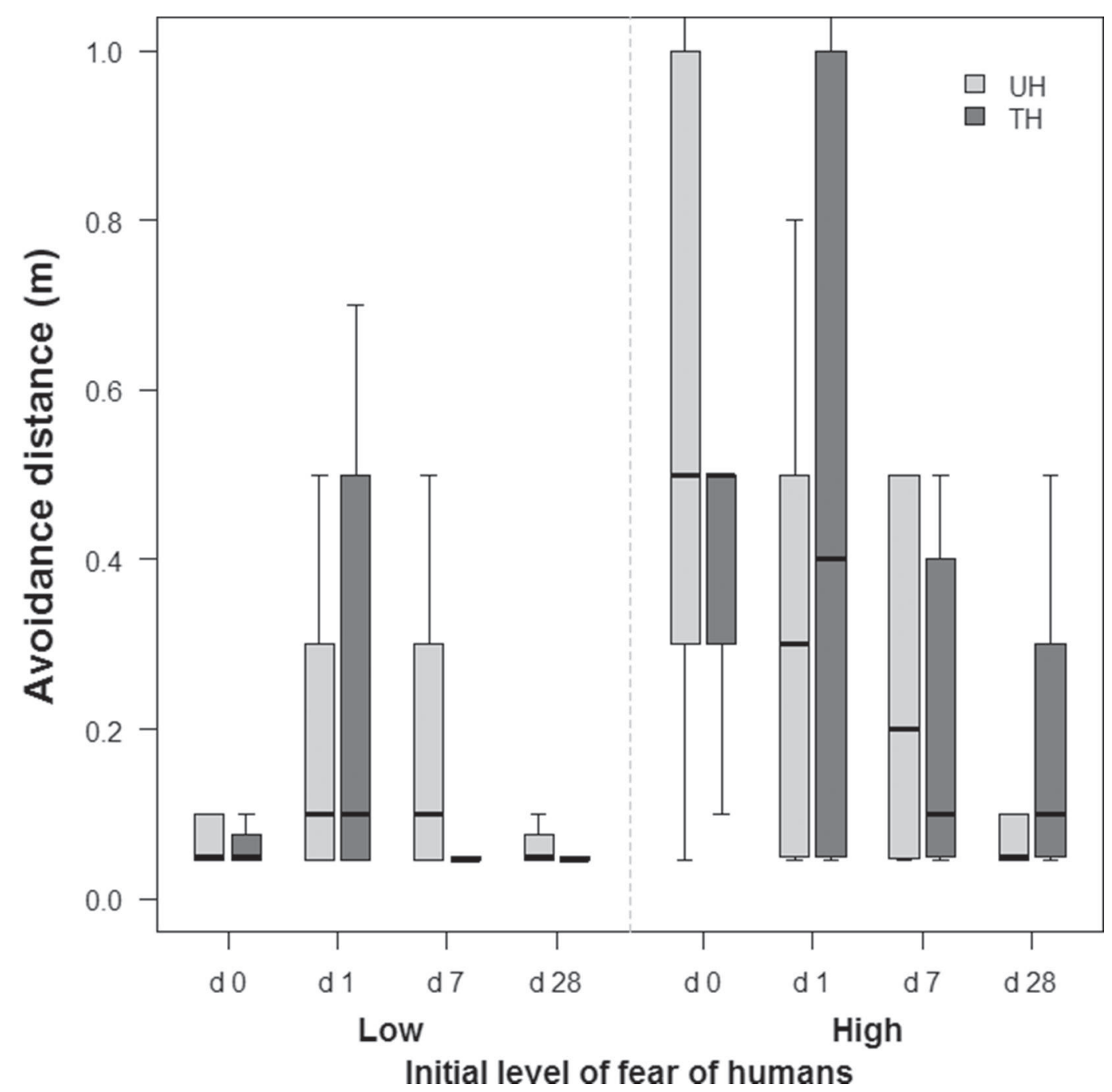

Figure 3. Human avoidance distances $(\mathrm{m})$ of trained $(\mathrm{TH})$ and untrained $(\mathrm{UH})$ heifers measured on a series of test days $(\mathrm{d} 0=$ day of integration into herd; d 1, d 7, and d $28=$ days postpartum). Heifers' initial level of fear was classified as low or high. Box and whiskers plot of raw data: boxes $=$ first and third quartiles; thick line $=$ median; whiskers $=$ data range

Apart from the head posture, we did not find any statistically detectable influence of the initial level of fear of humans on behavior in the parlor, cardiac activity, and milk yield. Therefore, we could not parallel the findings of Sutherland and Huddart (2012), who indicated that the effect of training animals in the milking parlor on behavioral and physiological responses was influenced by heifer temperament. In line with our results, Sutherland and Dowling (2014) reported that behavior recorded during cluster placement at milking (flinching, stepping, kicking) was not correlated with human avoidance distance measured 1 mo before calving in first-lactation heifers.

\section{Milk Yield}

Neither lifetime daily milk yield at 100 DIM, total milk yield in the first 100 DIM, or average milk yield per min differed between $\mathrm{TH}$ and $\mathrm{UH}$, nor did these outcome variables vary with any other of the investigated predictors (Table 1). Therefore, a farmer that habituates heifers to the milking parlor following the approach used in the current study is unlikely to see an immediate gain in productivity, or, in other words, increased productivity seems to be an unreliable incentive to conduct such a training. Similar to our results, Polikarpus et al. (2014) reported that prepartum ha- 
bituation to milking routine did not have an effect on milk yield of buffalo heifers, although trained animals performed significantly fewer steps and kicks during milking.

\section{CONCLUSIONS}

The results indicate that the training regimen applied in the present study habituated heifers to some extent to the milking routine. Trained heifers showed fewer signs of stress (i.e., less stepping and kicking) during milking, whereas untrained heifers had a higher probability of putting their ears flat on the head, clamping their tail between the hind legs, and having their eyes wide open. However, these behavioral differences were not associated with clear differences in cardiac activity. Training over a longer period or in a more intensive way than carried out in this study could possibly lead to more pronounced effects on stress and productivity.

\section{ACKNOWLEDGMENTS}

We thank all dairy farmers for their cooperation, U. Marolf and M. Keller for technical support, and B. Kürsteiner for technical advice on the heart rate measurements (all at Agroscope, Tänikon, Switzerland). The project was funded by the Federal Food Safety and Veterinary Office (FSVO, Bern, Switzerland; Project No. 2.10.03).

\section{REFERENCES}

Barton, K. 2014. MuMIn: Multi-model inference. R package version 1.10.5. Accessed May 21, 2015. http://CRAN.R-project.org/ package $=$ MuMIn

Bates, D., M. Maechler, B. Bolker, and S. Walker. 2014. lme4: Linear mixed-effects models using Eigen and S4. R package version 1.1-7. Accessed May 21, 2015. http://CRAN.R-project.org/ package $=$ lme 4 .

Bertenshaw, C., P. Rowlinson, H. Edge, S. Douglas, and R. Shiel. 2008. The effect of different degrees of 'positive' human-animal interaction during rearing on the welfare and subsequent production of commercial dairy heifers. Appl. Anim. Behav. Sci. 114:65-75.

Boissy, A., A. Aubert, L. Désiré, L. Greiveldinger, E. Delval, and I. Veissier. 2011. Cognitive sciences to relate ear postures to emotions in sheep. Anim. Welf. 20:47-56.

Breuer, K., P. H. Hemsworth, J. L. Barnett, L. R. Matthews, and G. J. Coleman. 2000. Behavioural response to humans and the productivity of commercial dairy cows. Appl. Anim. Behav. Sci. $66: 273-288$.

Das, K. S., and N. Das. 2004. Pre-partum udder massaging as a means for reduction of fear in primiparous cows at milking. Appl. Anim. Behav. Sci. 89:17-26.

Dodzi, M. S., and V. Muchenje. 2011. Avoidance-related behavioural variables and their relationship to milk yield in pasture-based dairy cows. Appl. Anim. Behav. Sci. 133:11-17.

Eicher, S. D., M. Schutz, F. Kearney, S. Willard, S. Bowers, S. Gandy, and K. Graves. 2007. Prepartum milking effects on parlour behaviour, endocrine and immune responses in Holstein heifers. J. Dairy Res. 74:417-424.
Gygax, L., I. Neuffer, C. Kaufmann, R. Hauser, and B. Wechsler. 2008. Restlessness behaviour, heart rate and heart rate variability of dairy cows milked in two types of automatic milking systems and auto-tandem milking parlours. Appl. Anim. Behav. Sci. 109:167-179.

Gygax, L., N. Reefmann, M. Wolf, and J. Langbein. 2013. Prefrontal cortex activity, sympatho-vagal reaction and behaviour distinguish between situations of feed reward and frustration in dwarf goats. Behav. Brain Res. 239:104-114.

Hemsworth, P. H., J. L. Barnett, A. J. Tilbrook, and C. Hansen. 1989. The effects of handling by humans at calving and during milking on the behaviour and milk cortisol concentrations of primiparous dairy cows. Appl. Anim. Behav. Sci. 22:313-326.

Hemsworth, P. H., G. J. Coleman, J. L. Barnett, and S. Borg. 2000 Relationships between human-animal interactions and productivity of commercial dairy cows. J. Anim. Sci. 78:2821-2831.

Hemsworth, P. H., M. Rice, M. G. Karlen, L. Calleja, J. L. Barnett, J. Nash, and G. J. Coleman. 2011. Human-animal interactions at abattoirs: Relationships between handling and animal stress in sheep and cattle. Appl. Anim. Behav. Sci. 135:24-33.

Hopster, H., and H. J. Blokhuis. 1994. Validation of heart rate monitor for measuring a stress response in dairy cows. Can. J. Anim. Sci. $74: 464-474$.

Ivemeyer, S., U. Knierim, and S. Waiblinger. 2011. Effect of humananimal relationship and management on udder health in Swiss dairy herds. J. Dairy Sci. 94:5890-5902.

Kauke, M., and P. Savary. 2010. Effect of noise and vibration in milking parlour on dairy cow. Agrarforsch. Schweiz 1:96-101.

Kovács, L., V. Jurkovich, M. Bakony, O. Szenci, P. Póti, and J. Tőzsér. 2014. Welfare implication of measuring heart rate and heart rate variability in dairy cattle: Literature review and conclusions for future research. Animal 8:316-330.

Neisen, G., B. Wechsler, and L. Gygax. 2009. Effects of the introduction of single heifers or pairs of heifers into dairy-cow herds on the temporal and spatial associations of heifers and cows. Appl. Anim. Behav. Sci. 119:127-136.

Polikarpus, A., F. Napolitano, F. Grasso, R. Di Palo, F. Zicarelli, D. Arney, and G. De Rosa. 2014. Effect of pre-partum habituation to milking routine on behaviour and lactation performance of buffalo heifers. Appl. Anim. Behav. Sci. 161:1-6.

Proctor, H. S., and G. Carder. 2014. Can ear postures reliably measure the positive emotional state of cows? Appl. Anim. Behav. Sci. $161: 20-27$.

R Core Team. 2013. R: A language and environment for statistical computing. R Foundation for Statistical Computing, Vienna, Austria. Accessed May 21, 2015. http://www.R-project.org/.

Reefmann, N., T. Muehlemann, B. Wechsler, and L. Gygax. 2012 Housing induced mood modulates reactions to emotional stimuli in sheep. Appl. Anim. Behav. Sci. 136:146-155.

Reefmann, N., B. Wechsler, and L. Gygax. 2009. Behavioural and physiological assessment of positive and negative emotion in sheep. Anim. Behav. 78:651-659.

Rousing, T., M. Bonde, J. H. Badsberg, and J. T. Sorensen. 2004. Stepping and kicking behaviour during milking in relation to response in human-animal interaction test and clinical health in loose housed dairy cows. Livest. Prod. Sci. 88:1-8.

Rushen, J., A. M. B. De Passille, and L. Munksgaard. 1999. Fear of people by cows and effects on milk yield, behavior, and heart rate at milking. J. Dairy Sci. 82:720-727.

Sandem, A. I., and B. O. Braastad. 2005. Effects of cow-calf separation on visible eye white and behaviour in dairy cows - A brief report. Appl. Anim. Behav. Sci. 95:233-239.

Sandem, A. I., A. M. Janczak, and B. O. Braastad. 2004. A short note on effects of exposure to a novel stimulus (umbrella) on behaviour and percentage of eye-white in cows. Appl. Anim. Behav. Sci. 89:309-314.

Schwalm, A., F. Brandes, H. Georg, H. J. Helke, T. Hinz, and G. Ude. 2012. Heart rates of heifers and cows in the milking parlour considering the habituation of heifers to the milking routine prior to calving and the noise level. Agric. For. Res. 62:51-57. 
Sutherland, M. A., and S. K. Dowling. 2014. The relationship between responsiveness of first-lactation heifers to humans and the behavioral response to milking and milk production measures. J. Vet. Behav. Clin. Appl. Res. 9:30-33.

Sutherland, M. A., and F. J. Huddart. 2012. The effect of training first-lactation heifers to the milking parlor on the behavioral reactivity to humans and the physiological and behavioral responses to milking and productivity. J. Dairy Sci. 95:6983-6993.

Sutherland, M. A., A. R. Rogers, and G. A. Verkerk. 2012. The effect of temperament and responsiveness towards humans on the behavior, physiology and milk production of multi-parous dairy cows in a familiar and novel milking environment. Physiol. Behav. 107:329-337.

Van Reenen, C. G., J. T. N. Van der Werf, R. M. Bruckmaier, H. Hopster, B. Engel, J. P. T. M. Noordhuizen, and H. J. Blokhuis. 2002. Individual differences in behavioral and physiological responsiveness of primiparous dairy cows to machine milking. J. Dairy Sci. $85: 2551-2561$ von Borell, E., J. Langbein, G. Després, S. Hansen, C. Leterrier, J. Marchant-Forde, R. Marchant-Forde, M. Minero, E. Mohr, A. Prunier, D. Valance, and I. Veissier. 2007. Heart rate variability as a measure of autonomic regulation of cardiac activity for assessing stress and welfare in farm animals - A review. Physiol. Behav. 92:293-316.

Waiblinger, S., C. Menke, and D. W. Fölsch. 2003. Influences on the avoidance and approach behaviour of dairy cows towards humans on 35 farms. Appl. Anim. Behav. Sci. 84:23-39.

Wicks, H. C. F., A. F. Carson, M. A. McCoy, and C. S. Mayne. 2004. Effects of habituation to the milking parlour on the milk production and reproductive performance of first calving Holstein-Friesian and Norwegian dairy herd replacements. Anim. Sci. 78:345-354.

Windschnurer, I., C. Schmied, X. Boivin, and S. Waiblinger. 2008. Reliability and inter-test relationship of tests for on-farm assessment of dairy cows' relationship to humans. Appl. Anim. Behav. Sci. 114:37-53. 